\title{
EYE-LASH IN THE LACRIMAL PUNCTUM *
}

BY

\author{
A. J. BOASE \\ UGANDA
}

THE arrest of an eye-lash in a lacrimal punctum is said to be a not infrequent occurrence, though many authoritative textbooks do not mention it. Those that do would appear to stress the factor of obstruction. Fuchs specifically alludes to this accident as affecting the lower punctum, from which one might infer an immunity for the upper in his experience.

The following case presents unusual features. The patient, a Goan male, aged 50 years, was seen in July, 1944, with an irritating right eye. There was marked conjunctival congestion on the nasal side, and between plica and limbus a small phlycten-like nodule which stained with fluorescein. He had had this trouble for 18 days, and was emphatic that the nodule was not there before the eye got red. Treatment with protargol and a lotion had not benefited him. On eversion of the upper lid, the root-end of a lash was seen protruding from the upper punctum. It was evident that the lash made contact with the nodule when the eyes converged for near, their normal position throughout his working day as clerk. The lash was removed and the nodule excised (an innocent granuloma). Healing was uneventful.

The patient returned in January, 1949, this time with his left eye inflamed for three days. Conjunctival injection was again limited to the nasal side, and in the middle of it was a small oedematous whitish area which stained with fluorescein. With the previous record before me, I immediately looked at the puncta, and had the satisfaction of removing a lash from the upper one, again with the root end protruding. A rapid cure followed.

The coincidence of this accident happening to both eyes is in itself remarkable, the more so as his puncta do not appear to differ from those of an average person. But of greater interest is the trauma and chronic inflammation which resulted on both occasions from this seemingly trivial mishap. In countless cases of trachoma, wherein short sharp stumpy lashes unceasingly insult the conjunctiva over long periods of time, I have never observed ulceration and granulation as seen in this case. Rather is the expected change one of keratinization. Does this suggest that the rough root of a lash is a more dangerous weapon than its opposite extremity? This theory is supported by another case in my experience where a lash was lodged in the orifice of a central upper meibomian gland with root protruding; it caused more distress than one usually sees with an aberrant lash.

It is to be noted that the factor of lacrimal obstruction did not enter into this case ; lacrimation there was, but for obvious reasons of irritation. But should one expect obstruction unless both puncta, or at least the lower one, are obstructed? 